\title{
The Bioscience of Merging Traditional Chinese Medicine with Western Medicine
}

\author{
Jim Schnell* \\ Fulbright Scholar Association, USA \\ *Corresponding author: Jim Schnell, Ph.D., Fulbright Scholar Association, USA
}

Submission: February 07, 2018; Published: February 22, 2018

\section{Introduction}

This article addresses the bioscience of merging Traditional Chinese Medicine [1] with western medicine. As such, it exemplifies the opening of China and the continued evolution of international relations correlated with the bioscience domain. "On November 15,2012 , the day he became general secretary of the Chinese Communist Party, Xi Jinping stood onstage at the Great Hall of the People, in Beijing, to reflect back on his country's 5,000 years of history. After citing China's 'indelible contribution' to world civilization, Xi called for 'the great revival of the Chinese nation' [2]. The scientific community is part of the foundation for future modernization and global linkages. There is a historical context for this.

The People's Republic of China is engaged in reforms which involve development of its economic, cultural, educational, and political processes. The need for reform was realized when China fell behind the development of the western world in many areas. China closed its doors to the outside world in 1949 and it experienced limited interaction with the outside world until reform began in 1979 .

The Cultural Revolution (1966-1976) was especially hard on development in China. During this period, political upheaval discouraged, and in some cases banned, technological developments. Since 1979, though, China has focused considerable emphasis on developing itself and promoting more interaction with the western world. One of the many areas which have received modernization efforts is medicine. The medical treatment in China is based on the practices of Traditional Chinese Medicine (TCM). Traditional Chinese Medicine has evolved during China's long history, which dates back over 5,000 years.

The effectiveness of TCM has not been questioned, but Chinese physicians have sought to better understand TCM by seeking interaction with western physicians. The intended result is that both Chinese and western medical practices can be enhanced through cross-cultural collaboration. Such cross-cultural collaboration has been enhanced via mass mediated venues.

In September 1981, the journal of Traditional Chinese Medicine was founded by the All-China Association of Traditional Chinese
Medicine and the Academy of Traditional Chinese Medicine (TCM). The journal was the first English periodical of Traditional Chinese Medicine published in China.

In the first issue Chui Yueli [3], President of the All-China Association of Traditional Chinese Medicine, states, "Traditional Chinese Medicine is not a treasure belonging to the Chinese people alone, but it is an integral part of world civilization and a common benefit for all mankind. All Chinese-Western collaboration has shown more satisfactory results than could have been expected with either western or traditional Chinese medicine alone" [3].

Traditional Chinese Medicine has proven to be effective within the Chinese culture, and some practices have been exported to western nations. One such example is acupuncture. Although Chinese practitioners are confident in their methods, and they have little problem explaining "how" the procedures are to be performed, they have expressed difficulty explaining "why" the procedures are effective.

Interaction with western physicians provides a climate whereby western physicians can learn more about "how" and "why" the procedures are effective. Thus, through the merging of TCM and western medicine, old ideas are being cross-culturally communicated through new perspectives. This article will discuss how considerations affecting the merging have evolved since the open-door reforms were initiated by the People's Republic of China in 1979 and how mass mediated venues have been part of that process.

Interaction between Chinese physicians and western physicians has increased significantly since the opening of China. Kie Zhufan [4], head of Traditional Chinese Medicine at Beijing Medical College, lectured and did research on the integration of TCM and western medical systems during a six month period in 1981 [4]. This is recognized as one of the seeds of the many exchanges which have occurred since.

A symposium sponsored by France's International Health Centre, held in April 1987, exemplifies the many medical exchanges which have occurred during the 1980s. A Chinese delegation met with government officials from ten western European nations 
during the three day symposium. "They had an in-depth exchange of views on western and Chinese traditional medicine, their different viewpoints and methods, and their past development and present state. They also explored fresh channels for greater cooperation in the field" [5].

Traditional Chinese Medicine is a legacy composed of centuries of experiences by the Chinese in dealing with disease. These experiences have evolved into a unique system of theories and beliefs. A discussion of medical exchange between China and the west must consider fundamental ideas of TCM, which are foreign to western medicine. The Yin and Yang and the five elements exemplify such ideas.

Yin and Yang holds that everything in the universe is composed of two opposite aspects which are constantly interdependent and in conflict. Water and fire symbolize basic properties of Yin and Yang. "That is to say, the basic properties of Yin stimulate those of water, including coldness, downward direction, dimness, etc., while the basic properties of Yang are like those of fire, including heat, upward direction, brightness, etc." [6].

The theory of the five elements maintains that wood, fire, earth, metal and water are the basic materials which comprise the physical world. A relationship of interdependence and interest raint exists among these elements. A fundamental premise of Traditional Chinese Medicine is to "classify natural phenomena, tissues and organs of the human body and human emotions, into different categories and to interpret the relationship between human physiology and pathology and the natural environment with the law of the inter-promoting, interacting, overacting, and counteracting of the five elements" [5]. This premise is central to their medical practice.

The merging of TCM with western medicine has been done effectively in a variety of areas. They have used combined Chinese and western medical means to treat acute abdomens, bone fracture, arthritis, soft tissue trauma, coronary heart disease. All have shown more satisfactory results than could have been expected with either western or Traditional Chinese Medicine alone. At the same time a deeper insight has been gained into the nature of certain diseases and the mechanisms for recovery [3]. The practice of acupuncture, the 3,000 year old Chinese practice of using needles to treat a wide range of illnesses, by western physicians has received much attention in the past decade. Acupuncture is now taught in the United States. The Hwa to Acupuncture Centre, in the Netherlands, was the first school in the west to grant full Chinese diplomas for acupuncture study. "The object of the whole exercise is to come to a synthesis of western medicine and Traditional Chinese Medicine in the hope it benefits patients" says Henk Termeulen, director of the Centre [7].

The combining of Traditional Chinese Medicine and western medicine has also been used for patients with orthopedic problems. Wang Congshu, president of Baoding Orthopedics Rehabilitation Hospital, cures orthopedic illnesses "by using qigong, or Chinese traditional breathing exercises, combined with other Chinese traditional and western methods" [8]. Benefits of combining approaches have also been realized in the radiation treatment of cancer [9] and the removal of gallstones [10].

Concern with the connection between mental well being and physical well being has received increased emphasis in the U.S. in the past 20 years. A similar emphasis has occurred in China. The Sino-Japan Friendship Hospital, founded in 1984, bases its approaches on western and TCM. Cheng Lirong, a nurse at the hospital, reports, "One characteristic of nursing is emotion nursing, similar to psychological nursing in the west" [11]. It is believed that seven emotional factors- joy, anger, melancholy, brooding, sorrow, fear, and shock can cause disease [11]

The merging of TCM with western medicine has produced many benefits, but there have been problems which have hindered the process. "Differences in historical backgrounds and language barriers still place some limits on international academic exchange concerning Traditional Chinese Medicine and integrated Chinese and western medicine. This is particularly so in the west, where many medical workers are unfamiliar with Traditional Chinese Medicine" [3].

Cultural norms have also hindered the exchange of medical practices. Blood transfusions have become more common in China "but it is still difficult to find enough donors because of a traditional Chinese fear of losing blood," reports Xing Lixiang, a senior official of the Beijing Blood Centre [12]. Yu Fangouing, director of the maternity ward at Beijing Hospital for Gynecology and Obstetrics, points out that many women are reluctant to use new practices based on scientific approaches. "They stick to their old-fashioned teachings of their mothers or in-laws and make a list of taboos after delivery abstaining from taking a bath, cleaning their teeth, eating fruits and getting out of bed within one month of delivery. Babies are completely bound up for one month" [13].

Another consideration which directly contrasts with practices in the west deals with wages for physicians and health care staff. Chinese physicians and health care staff make far less money than western physicians and staff. "A doctor in Beijing's Chaoyang Hospital has to see up to 60 patients a day but gets a monthly wage of less than 80 yuan (\$21 U.S.)" [14]. This amount is less than the wage of teachers in China, which is another low paying occupation. Thus, one can safely assume that the health care field in China is valued differently than it is in the United States (where medical doctors make much more money proportionate to their counterparts in China).

TCM has the potential of becoming a significant global force. Cultural imperialism often goes hand in hand with economic and militaristic imperialism. This has the potential to perpetuate a form of global culture that gives first billing to Chinese cultural components [15]. China is seeking to promote new markets beyond their borders. Extension of such new markets typically involves extension of geopolitical reach in that the new lines of global extension require protection. One can expect such context may serve as rationale for the projection of Chinese military capabilities [16]. 


\section{Conclusion}

These findings, taken together, present a context where the merging of TCM with western medicine in China exemplifies how old ideas can be cross-culturally communicated through new perspectives via mass mediated venues [17]. That is, Chinese medical approaches are explained through western perspectives and mass mediated venues are often a part of such transmission of knowledge. Though there are obstacles within this process, the benefits have been viewed as being well worth the challenges that have been encountered.

This report addresses benefits of such interaction, and some of the problems which have arisen, in hopes of better understanding a process that can continue to improve health care practices around the world [18]. It is evident that mass mediated venues will play a significant role in the conveyance of information within this process. Mass mediated venues include standard channels such as television [19], radio and newspaper along with the new communication technologies that involve internet-based channels and varied forms of social media. These types of mass media forms impact both the form and content of meanings being conveyed. We are on the door step of this evolution [20].

\section{References}

1. China Intercontinental (2011) Traditional Chinese Medicine. Cambridge University Press, New York, USA.

2. Economy E (2017) History with chinese characteristics: how china's imagined past shapes its present. Foreign Affairs pp. 141-148.

3. Yueli C (1981) A welcome event in international academic exchange on traditional chinese medicine. Journal of Traditional Chinese Medicine $1(1)$.

4. Kie Zhufan (1981) Kie Zhufan invited to lecture in USA. Journal of Traditional Chinese Medicine 1(2): 97.

5. (1987) East west work urged in medicine. China Daily, p. 4.

6. (1981) Lectures on essentials of traditional chinese medicine. Journal of Traditional Chinese Medicine 1(1): 73.

7. (1987) Chance meeting spawns acupuncture centre. China Daily, p. 1.

8. (1987) Old and new combine to heal. China Daily, p. 6.

9. (1987) China leads in cancer treatment. China Daily, p. 3.

10. (1987) Shock waves remove gallstones. China Daily, p. 5.

11. Jianhua A (1987) Nurse tailors her care. China Daily, p. 6.

12. Tingting Z (1987) Blood donors get new incentives. China Daily, p. 3.

13. Manhong S (1987) Teaching science of nurture. China Daily, p. 5.

14. Guanfeng C (1987) Top expert warns of shortage of doctors. China Daily, p. 1.

15. Chow V (2017) Silk road may boost film reach. Variety, pp. 16-18.

16. Layne C (2017) Contemplating decline: china's challenge to America percolates on many fronts. The American Conservative, pp. 29-33.

17. Ching F (2007) Chinese Herbal Drug Research Trends. Nova Scotia Publishers, New York, USA.

18. Cuellar N (2006) Conversations in complementary and alternative medicine. In: Sudbury MA (Ed.), Jones \& Bartlett Publishers, USA.

19. Garran T (2008) Western herbs according to traditional chinese medicine. Rochester, Healing Arts Press, VT, USA.

20. Meizhong Y (1981) To my colleagues. Journal of Traditional Chinese Medicine 1(1): 1.
Creative Commons Attribution 4.0 International License

\section{Submit Article}

\section{Your subsequent submission with Crimson Publishers} will attain the below benefits

- High-level peer review and editorial services

- Freely accessible online immediately upon publication

- Authors retain the copyright to their work

- Licensing it under a Creative Commons license

- Visibility through different online platforms

- Global attainment for your research

- Article availability in different formats (Pdf, E-pub, Full Text)

- Endless customer service

- Reasonable Membership services

- Reprints availability upon request

- One step article tracking system 